\title{
Stabilization and Sterilization of Pericardial Scaffolds by Ultraviolet and Low-Energy Electron Irradiation
}

\author{
Simona Walker, MSc, Jessy Schönfelder, Dr. rer. Medic, ${ }^{1}$ Sems-Malte Tugtekin, Prof. Dr. Med, ${ }^{2}$ \\ Christiane Wetzel, Dr. Ing. habil, ${ }^{1}$ Michael C. Hacker, Dr. rer. nat. habil,, ${ }^{3}$ and Michaela Schulz-Siegmund, Prof. Dr. rer. nat ${ }^{3}$
}

Pericardial scaffolds have a wide spectrum of clinical applications ranging from patches for vascular reconstruction and abdominal wall defects to bioprosthetic heart valves. The current gold standard of tissue preparation involves disinfection and cross-linking using glutaraldehyde. However, glutaraldehyde-associated toxicity as well as rapid calcification and premature graft failure represent the major modes of failure. ${ }^{1}$ Therefore, a variety of alternative strategies for tissue conservation have been pursued. However, none of those strategies has substituted glutaraldehyde as the method of choice yet. Furthermore, safe sterilization procedures that are nondetrimental to the tissue's functionality are scarce. We have developed a novel procedure to stabilize and sterilize (S) acellular pericardial scaffolds combining photo-initiated ultraviolet cross-linking (U) with low-energy electron irradiation (LEEI). This SULEEI procedure avoids the use of glutaraldehyde and utilizes LEEI as effective sterilization method. A bioburden of $5.1 \times 10^{5} \pm 4.6 \times 10^{5}$ viable bacteria could be successfully inactivated by SULEEI treatment applying a surface dose of $30.6 \pm 2.8 \mathrm{kGy}$. By challenging high-density polyethylene foil stacks with $>10^{6}$ Bacillus pumilus spores in different depths and modeling the dose distribution within the scaffolds, a maximum sample thickness of $175 \mu \mathrm{m}$ was determined for successful sterilization. Moreover, SULEEI treatment appeared nondetrimental to the ultimate tensile strength $(17.6 \pm 8.6 \mathrm{MPa}$ vs. $17.4 \pm 9.6 \mathrm{MPa})$ of the scaffolds compared with glutaraldehyde-treated pericardia. Cell number and overall metabolic activity of human endothelial cells were significantly higher on SULEEI-treated pericardia compared with control samples. In contrast, no cell proliferation could be detected on glutaraldehyde-treated pericardia. Thus, the SULEEI procedure may be a promising novel procedure for glutaraldehyde-free tissue preparation for pericardium-based tissue transplants and tissue engineering.

Keywords: pericardium, low-energy electron irradiation, ionizing irradiation, sterilization, glutaraldehyde, SULEEI

\section{Impact Statement}

Pericardium-based tissue transplantation is a lifesaving treatment. Commercial glutaraldehyde-treated pericardial tissue exhibits cytotoxicity, which is associated with the accelerated graft failure. Replacement of glutaraldehyde has been suggested to overcome those drawbacks. In this study, we report a toxin-free method that combines tissue stabilization with a terminal sterilization. Our data indicate that the SULEEI procedure, which is part of an issued patent, may be a promising first step toward glutaraldehyde-free pericardium-based tissue transplants. Thus, our results may contribute to improving cardiovascular treatment strategies.

\section{Introduction}

$\mathbf{P}$ ERICARDIAL TISSUE IS in use for a wide spectrum of clinical applications, including patches for vascular reconstruction, abdominal wall defects, and bioprosthetic heart valves. ${ }^{2-5}$ Approximately 600,000 vascular grafts, $20,000,000$ patches for abdominal wall repair, and 110,000 bioprosthetic heart valves are transplanted annually worldwide. ${ }^{6-8}$ Since native as well as decellularized xenogeneic pericardia are quickly resorbed in vivo, ${ }^{9,10}$ cross-linking

\footnotetext{
${ }^{1}$ Fraunhofer Institute for Organic Electronics, Electron Beam and Plasma Technology FEP, Dresden, Germany.

${ }^{2}$ Department of Cardiac Surgery, Faculty of Medicine CGC, Technische Universität Dresden, Herzzentrum Dresden, Dresden, Germany.

${ }^{3}$ Institute of Pharmacy, Pharmaceutical Technology, Faculty of Medicine, Leipzig University, Leipzig, Germany.
}

(C) Simona Walker, et al., 2018; Published by Mary Ann Liebert, Inc. This Open Access article is distributed under the terms of the Creative Commons License (http://creativecommons.org/licenses/by/4.0), which permits unrestricted use, distribution, and reproduction in any medium, provided the original work is properly cited. 
with glutaraldehyde is the current gold standard for the conservation of pericardial scaffolds. ${ }^{11,12}$

Despite the cross-linking and disinfecting capacity, cytotoxicity as well as accelerated graft failure due to tissue calcification have been associated with glutaraldehyde treatment. ${ }^{13}$ To overcome those drawbacks, a large number of anticalcification treatments as well as alternative crosslinking strategies have been followed. Compounds that show a lower degree of cytotoxicity including carbodiimides, proanthocyanidin, triglycidylamine, and genipin as well as nontoxic radical scavengers including riboflavin or ascorbate or a combination of various compounds have been evaluated for stabilization of collagen-rich tissues. ${ }^{14-18}$

Sterilization of biological tissues has been challenging. Ideally, a safe sterilization that is nondetrimental to the tissue is warranted. Ionizing irradiation is an established procedure for sterilization of medical products such as surgical instruments according to DIN EN ISO $11137 .{ }^{19}$ During ionizing irradiation, the occurrence of free radicals leads to the eradication of pathogens as well as nonspecific modifications of the substrate. ${ }^{20}$ Low-energy electron irradiation (LEEI) (accelerating voltage of $\leq 300 \mathrm{kV}$ ) has been suggested to be particularly gentle to protein structures. We could recently show that the structure of various virus proteins is almost indistinguishable from that of active pathogens after LEEI treatment. ${ }^{21,22}$ In contrast, high-energy electron irradiation (HEEI) (accelerating voltage of $>300 \mathrm{kV}$ ) using similar doses as in our study on virus inactivation has been shown to damage tendon allograft structure, which results in decreased mechanical properties. ${ }^{23,24}$ Gamma irradiation has been reported to lead to fibril reorganization, protein denaturation, collagen fragmentation, and condensation of collagen-rich tissues. ${ }^{14,25-27}$ An important advantage of LEEI is its low penetration depth, which is considerably lower compared with HEEI and therefore minimal shielding (in this study: $8 \mathrm{~mm}$ of lead) is sufficient for protection against collateral X-rays. ${ }^{28}$ This allows for the integration of LEEI facilities directly at the location of the user such as in hospitals, tissue banks, or good manufacturing practice laboratories.

Here, we have developed a novel procedure for sterilization (S) and photo-initiated ultraviolet (UV) cross-linking (U) of decellularized pericardial scaffolds combining UV irradiation and LEEI (Fig. 1), the SULEEI procedure. This alternative to glutaraldehyde warranted to overcome tissue cytotoxicity while concurrently improving material properties favorable for pericardium-based tissue transplants. The feasibility of sterilizing pericardial scaffolds by LEEI and the influence of the SULEEI procedure on material properties of the pericardial scaffolds were evaluated by analysis of the enzymatic resistance, the mechanical properties, cy- tocompatibility, and tissue morphology. Pericardia treated by the SULEEI procedure are referred to as riboflavin/UVLEEI-treated pericardia.

\section{Materials and Methods}

\section{Tissue preparation and treatment}

Porcine pericardia from 3- to 6-month-old pigs were kindly provided by a local slaughterhouse (Fleischerei Peter, Eschdorf, Germany). Pericardia were obtained under clean conditions, transported to the laboratory in phosphatebuffered saline (PBS) at $4^{\circ} \mathrm{C}$, and immediately dissected. Decellularization was carried out as described by Roosens et al. ${ }^{29}$ Protocols of the different treatment groups are shown in Table 1. Supple Peri-Guard ${ }^{\circledR}$ (Lamed GmbH, Germany) and Edwards bovine pericardial patch (Edwards Lifesciences Services GmbH, Germany) were kindly provided by the manufacturers. Before analysis, commercial pericardial patches were washed according to the manufacturer's recommendations.

\section{UV irradiation}

Pericardial tissue was treated with $260 \mu \mathrm{M}$ riboflavin (Serva, Germany) and 2\% dextran T500 (Carl Roth, Germany) for at least $24 \mathrm{~h}$. To prevent drying, samples were placed on filter paper immersed in riboflavin/dextran solution and irradiated with $570 \mathrm{~mJ} / \mathrm{cm}^{2} \mathrm{UV}(320-480 \mathrm{~nm})$ within $30 \mathrm{~min}$.

\section{Low-energy electron irradiation}

LEEI was carried out for sterilization and modification of pericardial tissue. Pericardia were irradiated in a nitrogen-rich atmosphere (oxygen concentration $<100 \mathrm{ppm}$ ). Pericardia were wrapped in polyethylene (PE) foil before irradiation for sterility testing or irradiated unpackaged (all other analyses). For LEEI, an accelerating voltage of $150 \mathrm{kV}$, a beam current of $3 \mathrm{~mA}$, and a working distance of $60 \mathrm{~mm}$ were used. The dose was adjusted by adjusting the exposure time to the beam. To obtain a homogeneous dose distribution within the tissue, the pericardia were irradiated from both sides. The applied dose was monitored for every run using the radiochromic Ris $\varnothing$ B3 film dosimeter (Ris $\varnothing$ High Dose Reference Laboratory, Denmark) (thickness $18.4 \mu \mathrm{m}$, density $\left.1.12 \mathrm{~g} / \mathrm{cm}^{3}\right){ }^{30}$

\section{Quantification of DNA content}

Decellularization efficiency was evaluated by quantification of DNA content using the DNeasy Blood \& Tissue
FIG. 1. Schematic diagram of the SULEEI procedure. After decellularization of pericardial tissue (step I), pericardia were soaked in riboflavin and UV irradiated (step II) and finally treated with low-energy electron irradiation (step III). UV, ultraviolet; LEEI, low-energy electron irradiation.

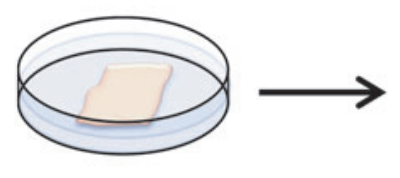

Step I Decellularization

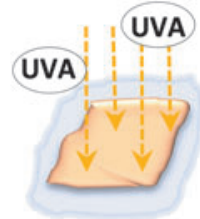

Step IIPhoto-initiated UV pre-crosslinking

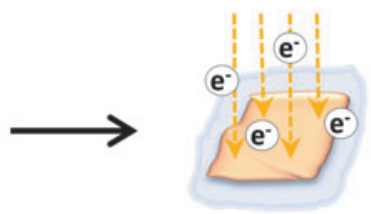

Step III -

Sterilization by lowenergy electron irradiation 
Table 1. Protocols Used for the Different Treatment Groups

\begin{tabular}{|c|c|}
\hline Group & Treatment \\
\hline Native & Native pericardia were stored in PBS at $4^{\circ} \mathrm{C}$ (control group). \\
\hline Glutaraldehyde & $\begin{array}{l}\text { Pericardia were cross-linked for } 30 \text { minutes with } 0.2 \% \text { glutaraldehyde (Applichem, Germany), } \\
\text { washed several times, and stored in PBS at } 4^{\circ} \mathrm{C} \text { (control group). }\end{array}$ \\
\hline dGlutaraldehyde & $\begin{array}{l}\text { Pericardia were decellularized as described below and cross-linked with glutaraldehyde as } \\
\text { described above (control group). }\end{array}$ \\
\hline Decellularized & $\begin{array}{l}\text { Pericardia were incubated in } 5 \mathrm{mM} \text { Tris buffer ( } \mathrm{pH} 8 \text { ) for } 24 \mathrm{~h} \text { at } 4^{\circ} \mathrm{C} \text {. Then, the solution was } \\
\text { replaced by fresh } 5 \mathrm{mM} \text { Tris buffer containing } 1 \% \text { Triton-X-100 (Carl Roth, Germany) for } \\
24 \mathrm{~h} \text { at } 4^{\circ} \mathrm{C} \text {. Next, samples were washed twice for } 15 \mathrm{~min} \text { in HBSS (Carl Roth, Germany) at } \\
4^{\circ} \mathrm{C} \text {. Subsequently, samples were incubated twice with Hanks Balanced Salt Solution (HBSS) } \\
\text { containing } 100 \mathrm{mg} / \mathrm{mL} \text { DNAse I (Serva, Germany), } 20 \mathrm{mg} / \mathrm{mL} \text { RNAse A (Serva, Germany), } \\
\text { and } 100 \mathrm{mg} / \mathrm{mL} \text { Trypsin (Biochrom, Germany) for } 45 \mathrm{~min} \text { at } 37^{\circ} \mathrm{C} \text {. Samples were incubated in } \\
\text { fresh } 5 \mathrm{mM} \text { Tris buffer containing } 1 \% \text { Triton-X-100 for } 24 \mathrm{~h} \text { at } 4^{\circ} \mathrm{C} \text {. Samples were washed a } \\
\text { few times in PBS at } 4^{\circ} \mathrm{C} \text { (according to Roosens et al. }{ }^{29} \text { ). }\end{array}$ \\
\hline Decellularized-LEEI & Pericardia were decellularized as described above followed by treatment with LEEI. \\
\hline Riboflavin/UV-LEEI & $\begin{array}{l}\text { Pericardial tissue was decellularized as described above and treated with } 260 \mu \mathrm{M} \text { riboflavin } \\
\text { (Serva, Germany) and } 2 \% \text { dextran T500 (Carl Roth, Germany) for at least } 24 \mathrm{~h} \text {. To prevent } \\
\text { drying, samples were placed on filter paper immersed in riboflavin/dextran solution and } \\
\text { irradiated with } 570 \mathrm{~mJ} / \mathrm{cm}^{2} \text { UVA. }\end{array}$ \\
\hline Glucose-LEEI & $\begin{array}{l}\text { Pericardia were decellularized as described above, soaked in } 10 \mathrm{mM} \text { glucose (Merck, Germany) } \\
\text { for at least } 24 \mathrm{~h} \text {, and LEEI as described above. }\end{array}$ \\
\hline Ascorbate-LEEI & $\begin{array}{l}\text { Pericardia were decellularized as described above, soaked in } 10 \mathrm{mM} \text { ascorbate (Carl Roth, } \\
\text { Germany) for at least } 24 \mathrm{~h} \text {, and LEEI as described above. }\end{array}$ \\
\hline
\end{tabular}

HBSS, Hank's balanced salt solution; LEEI, low-energy electron irradiation; PBS, phosphate-buffered saline; UV, ultraviolet.

Kit (Qiagen, Germany) according to the manufacturer's recommendation. DNA content was analyzed using the NanoQuant Plate ${ }^{\mathrm{TM}}$ and infinite M200 plate reader (TECAN, Germany). The DNA content was indicated as nanograms of DNA per milligram of the corresponding dry weight.

\section{Collagenase digestion}

Pericardia were incubated in $0.4 \mathrm{U} / \mathrm{mL}$ Collagenase NB 8 Broad Range (Serva, Germany) in $50 \mathrm{mM}$ Tris buffer for $3 \mathrm{~h}$ at $37^{\circ} \mathrm{C}$ under constant agitation. Before and after digestion, the pericardia were dabbed four times on an absorbent wipe and the wet weight of the pericardia was determined. The relative weight was calculated by dividing the remaining weight by the initial weight of each sample.

\section{Determination of the bioburden}

For bioburden determination, pericardia were prepared as described above. Instead of irradiation, samples were placed in $3 \mathrm{~mL}$ caseine peptone soybean flower peptone bouillon (CASO) and vortexed for $2 \mathrm{~min}$ to detach bacteria from the samples. CASO bouillon was plated on CASO agar for viable counts.

The bioburden determination was validated by inoculation of pericardia with 100 colony forming units (CFU) Bacillus pumilus spores (MesaLab, France). Bacteria were detached and counted as described above. In parallel, $100 \mathrm{CFU}$ B. pumilus were directly inoculated into CASO bouillon. Inoculation was confirmed by viable counts. To compensate for incomplete recovery, the recovery factor was used to determine the overall bioburden $\left(\right.$ recovery factor $\left.=\frac{\text { number of inoculated bacteria }}{\text { number of recovered bacteria }}\right) \cdot{ }^{19,31}$

\section{Sterility assessment}

Irradiated pericardia were carefully unpacked under a laminar flow hood, transferred to sterile CASO bouillon, and incubated at $30^{\circ} \mathrm{C}$ for 14 days. A clear solution indicated a sterile pericardium, whereas a turbid solution indicated a nonsterile pericardium. As a positive control indicating the absence of inactivating antibiotics, pericardia were inoculated with $100 \mathrm{CFU}$ B. pumilus spores (MesaLab, France) and incubated in $3 \mathrm{~mL}$ CASO bouillon at $30^{\circ} \mathrm{C}$ for 14 days. A turbid solution indicated an absent or nonsufficient antimicrobial activity of the pericardium and a successful validation of the sterility assessment. ${ }^{19,31}$

\section{Simulation of the sterilization depth}

A stack of 4, 8, 12, 16, 20, and 26 high-density polyethylene (HDPE) foil disks (Pütz Folien, Germany) (thickness $12 \mu \mathrm{m}$, density $0.95 \mathrm{~g} / \mathrm{cm}^{3}$ ) was assembled to obtain different thicknesses. The foil in the center of the stack was inoculated with $1.5 \times 10^{6} \mathrm{CFU} B$. pumilus spores per square centimeter (MesaLab, France) and dried for $12 \mathrm{~h}$. HDPE foil stacks were packed in PE foil, sealed, and irradiated as described above. After LEEI, samples were carefully unwrapped and transferred to sterile CASO bouillon. Samples were vortexed for $2 \mathrm{~min}$ to detach spores from the HDPE foil. CASO bouillon was plated on CASO agar for viability counts. The CASO bouillon-foil suspension was incubated for 14 days at $30^{\circ} \mathrm{C}$ for sterility assessment as described above. To analyze the dose applied to the $B$. pumilus spores, a stack of $6,10,13$, and 17 film dosimeters were irradiated from both sides. After irradiation, the stacks were disassembled and the dose that reached each layer was analyzed. From these data, a polynomial regression correlating dose and sample depth was derived (OriginPro 2016). With 
this regression function, the expected dose at any position within a (tissue) sample was calculated. To confirm the correlation between the penetration depth of the film dosimeter and the pericardial tissue, a sandwich of a film dosimeter surrounded by a pericardium at either side was irradiated from two sides and the dose in the center was recorded.

\section{Uniaxial tensile test}

Uniaxial tensile test was carried out using the Film tester (EZ-Tester; Hegewald \& Peschke Mess- und Prüftechnik GmbH, Germany). Rectangular wet pericardial samples $(10 \times 20 \mathrm{~mm})$ were cut in an apex-to-base direction to compensate for potential direction-dependent effects. Tissue thickness was measured using a foil thickness gauge Model 497 (Erichsen Testing Equipment, Germany). Pericardia were placed on a filter paper and fixed in the clamps. After fixation, the filter paper was removed. Samples were longitudinally elongated at $23^{\circ} \mathrm{C}$ using a preload of $0.2 \mathrm{~N}$ and a strain rate of $4 \mathrm{~mm} / \mathrm{min}$. The measurement was stopped at a force reduction of $50 \%$. The stress was calculated by dividing the force by the cross-section. The strain was calculated by dividing the elongation by the initial length of the sample. Young's modulus was calculated by linear regression within the linear region at $10 \%$ strain. Ultimate tensile strength and strain at fracture were derived from the data sets.

\section{Cytocompatibility assessment}

Pristine pericardia were disinfected using Polysept ${ }^{\circledR}$ solution (Dermapharm AG, Germany) for 15 min and subsequently washed three times for $10 \mathrm{~min}$ with sterile PBS. Pericardia were then placed into well plates to avoid folding of the pericardium. A glass ring (inner diameter of $12.7 \mathrm{~mm}$ ) was placed on the pericardium to obtain equal surface areas between samples. Human umbilical vein endothelial cells (HUVEC) (PromoCell, Germany) were cultured in endothelial cell growth medium 2 (PromoCell, Germany) supplemented with $10 \mathrm{U} / \mathrm{mL}$ penicillin and $100 \mu \mathrm{g} / \mathrm{mL}$ streptomycin at $37^{\circ} \mathrm{C}$ in a humid atmosphere and $5 \% \mathrm{CO}_{2}$. Experiments were performed at passage 5 . Cells were seeded on the pericardial surfaces at a density of $2.3 \times 10^{4}$ cells per square centimeter. After 48 and $96 \mathrm{~h}$, the supernatant was removed and replaced by fresh medium containing 10\% resazurin (Biotinum, Germany). Two hours after a medium change, the fluorescence was measured at an excitation wavelength of $560 \mathrm{~nm}$ and an emission wavelength of $690 \mathrm{~nm}$ using the infinite M200 plate reader (TECAN, Germany).

Cell number and morphology were assessed using fluorescence microscopy. Cells were washed once with PBS and then fixed with $4 \%$ formaldehyde solution (AppliChem, Germany) for $10 \mathrm{~min}$. Thereafter, samples were washed three times with PBS and subsequently permeabilized for 5 min with PBS containing 0.5\% Triton-X-100 (Carl Roth, Germany). Samples were washed three times with PBS, and unspecific binding sites were blocked with blocking buffer ( $2 \%$ fetal calf serum [Biochrom, Germany] in PBS). Actin cytoskeleton was stained with $10 \mu \mathrm{M}$ PhalloidinTRITC (Sigma-Aldrich, Germany) in blocking buffer for $1 \mathrm{~h}$. After three washing steps with PBS, samples were incubated with $20 \mu \mathrm{g} / \mathrm{mL}$ DAPI (AppliChem, Germany) for $5 \mathrm{~min}$. After removal of the staining solution, samples were mounted with Roti-Mount FluorCare (Carl Roth, Germany). Cell morphology was analyzed using an Olympus BX61 fluorescence microscope. Cell number was determined as the number of DAPI-stained nuclei using the CellProfiler software.

\section{Histological analysis}

Pericardia were fixed in 4\% paraformaldehyde (AppliChem, Germany) in PBS, embedded in paraffin, and cut into 4$6 \mu \mathrm{m}$ thick sections. Decellularization efficiency as well as tissue morphology were assessed using hematoxylin and eosin staining following standard staining protocol. The fiber density was analyzed by quantification of the eosinstained area of histological cross-sections after hematoxylin and eosin staining and subsequent thresholding using ImageJ 1.46r (National Institute of Health). ${ }^{32}$ Ten randomly selected areas $(200 \times 80 \mu \mathrm{m})$ from three to four different animals and two to three different tissue sections each were used for analysis.

\section{Scanning electron microscopy}

Samples were dehydrated by immersion in ethanol series and dried using critical point drying according to the manufacturer's recommendation (EM CPD300; Leica Leica Methoden Microsystems $\mathrm{GmbH}$ ). By sputtering, a 6-8 mm thick gold layer was applied. Samples were analyzed in a scanning electron microscope (Zeiss DSM 962) using an acceleration voltage of $15 \mathrm{kV}$ and a working distance of $8 \mathrm{~mm}$.

\section{Statistical analysis}

Statistical analysis was carried out using the GraphPadPrism 6.01 software. Gaussian distribution of the data was analyzed by D'Agostino-Pearson omnibus normality test. To compare two groups that did not follow the Gaussian distribution, the Mann-Whitney test was used. More than two groups that were normally distributed were compared by one-way analysis of variance followed by Bonferroni's multiple comparison test. If more than two groups were compared that failed the normality criterion, a Kruskal-Wallis test followed by Dunn's multiple comparisons test was performed. The mean of a group of measured samples was compared with the calculated value by one sample $t$-test. Values of $p \leq 0.05, p \leq 0.01$, and $p \leq 0.001$ were considered statistically significant, depending on the individual experiment.

\section{Results \\ Decellularization}

Decellularization efficiency was evaluated by histology as well as analysis of the remaining DNA content. Hematoxylin and eosin staining of decellularized pericardia revealed no nuclear components in any of the analyzed sections (Fig. 7B). Analysis of remaining DNA content showed a 70fold reduction in DNA content from $1324 \mathrm{ng} / \mathrm{mg}$ corresponding dry weight to $18 \mathrm{ng} / \mathrm{mg}$ corresponding dry weight $(p \leq 0.001)$ (Fig. 2). 


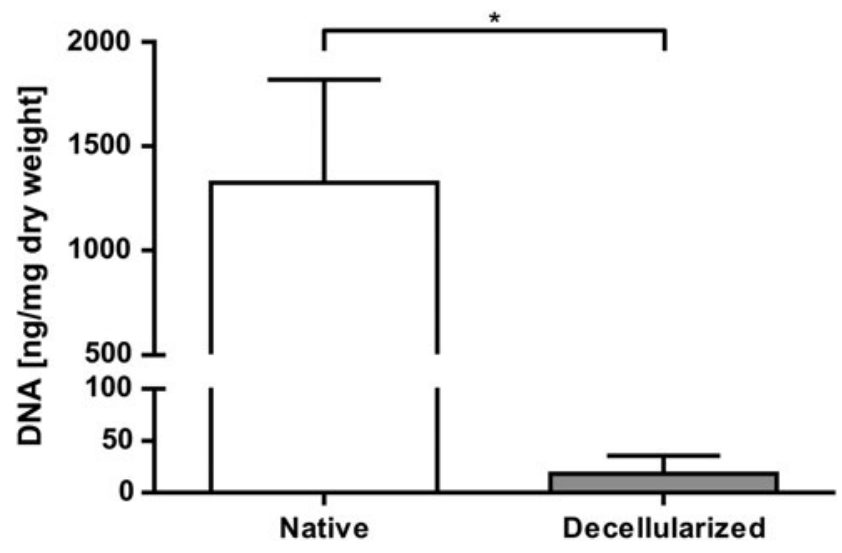

FIG. 2. Evaluation of the remaining DNA content after pericardium decellularization. DNA was extracted and the DNA content is shown as nanograms of DNA per milligram of the corresponding dry weight. Data are shown as means + $\mathrm{SD}(n=9)$. For statistical analysis, the Mann-Whitney test with a significance level of $p \leq 0.001$ (*) was applied.

\section{Biodegradability}

Collagenase resistance was analyzed as a measure for in vivo biodegradability of pericardia. Glutaraldehydetreated pericardia lost $20 \%$ of their initial weight in the course of $3 \mathrm{~h}$ (Fig. 3). In contrast, decellularized pericardia lost $81 \%$ of their initial weight. LEEI of samples did not lead to a further weight reduction. Neither the addition of glucose, ascorbate, nor riboflavin alone could increase the remaining weight after $3 \mathrm{~h}(p>0.05)$. After cross-linking and sterilization of decellularized pericardia with riboflavin, $\mathrm{UV}$, and LEEI, the collagenase resistance was significantly increased compared with nonirradiated controls $(p \leq 0.001)$. Fifty-nine percent of the tissue was digested after $3 \mathrm{~h}$, whereas more than $80 \%$ of tissue was lost in the nonirradiated controls and $20 \%$ of the glutaraldehyde-treated tissue (Fig. 3). Due to their improved collagenase resistance, riboflavin/UV and LEEI-treated pericardia were further assessed.

\section{Sterilization}

To estimate the germ reduction by LEEI, the bioburden on riboflavin/UV-treated pericardia was determined. A recovery factor of 1.7 was used for bioburden calculation $\left(n=5\right.$, data not shown). ${ }^{19} 5.1 \times 10^{5} \pm 4.6 \times 10^{5} \mathrm{CFU} / \mathrm{cm}^{2}$ viable bacteria could be detected on riboflavin/UV-treated pericardia (means $\pm \mathrm{SD}, n=20$ ). After LEEI, $100 \%$ of pericardia treated with riboflavin/UV became sterile (Table 2). The treatment with glutaraldehyde or riboflavin/UV alone, however, was not sufficient for sterilization (Table 2).

The penetration depth of electrons into a substrate is mainly determined by the density of the substrate as well as the accelerating voltage used for LEEI. ${ }^{33}$ Since the densities of the different materials used were alike but not equal (density film dosimeter: $1.12 \mathrm{~g} / \mathrm{cm}^{3}$, 30 density pericardium: $1.04 \mathrm{~g} / \mathrm{cm}^{3},{ }^{34}$ density HDPE foil: $0.95 \mathrm{~g} / \mathrm{cm}^{3}$ ), all thicknesses specified were adjusted to correspond to the density of pericardial tissue. The mean thickness of riboflavin/ UV-LEEI-treated pericardia was $101 \pm 32 \mu \mathrm{m}$ (Fig. 4A). Glutaraldehyde-treated pericardia were significantly thicker $(150 \pm 43 \mu \mathrm{m}, p \leq 0.01)$ compared with riboflavin/UV-LEEI-

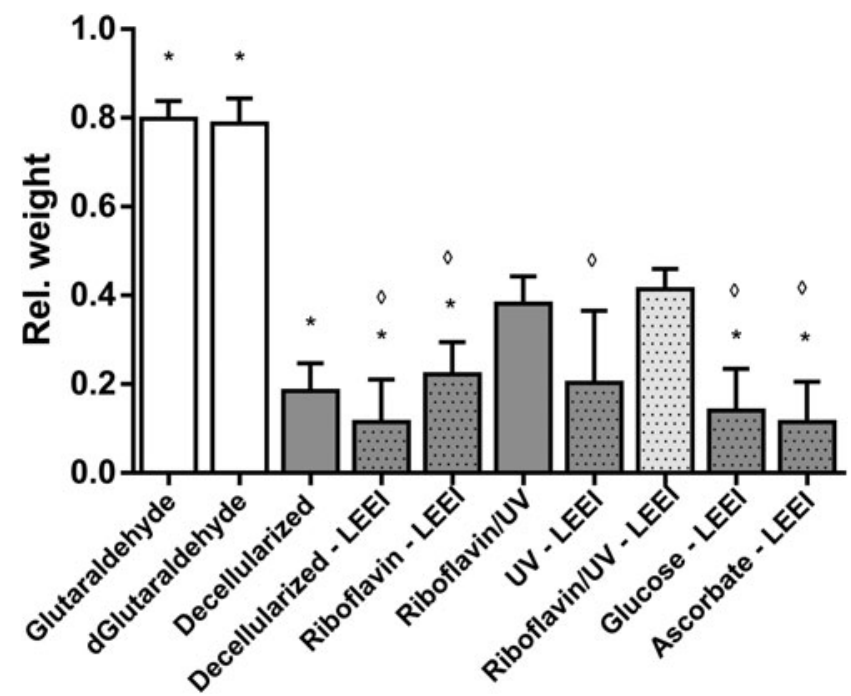

FIG. 3. In vitro enzymatic resistance of pericardia. Differently treated pericardia (Table 1) were digested for $3 \mathrm{~h}$ with $0.4 \mathrm{U} / \mathrm{mL}$ collagenase 1 . Before and after digestion, the wet weight was determined and indicated relative to the initial weight of each sample. Dotted bars indicate LEEItreated pericardia. Except glutaraldehyde-treated pericardia, all pericardia were decellularized. Data are shown as means $+\mathrm{SD}(n=9)$. Statistically significant differences were analyzed by one-way ANOVA followed by Bonferroni's multiple comparisons test. Statistically significant differences $(* p \leq 0.001)$ of groups compared with riboflavin/UV-LEEItreated pericardia and statistically significant differences $(\diamond p \leq 0.01)$ of groups compared with riboflavin/UV-treated pericardia were indicated. Differences between glutaraldehydeas well as dGlutaraldehyde-treated samples and all other treatment groups were statistically significant $(p \leq 0.001)$. No further statistically significant differences were detected. ANOVA, analysis of variance.

treated pericardia. All other treatment groups did not show significantly different thicknesses compared with riboflavin/ UV-LEEI-treated pericardia (Fig. 4A). To model the dose distribution within the pericardial tissue, a stack of six layers of radiochromic film dosimeters with a thickness of $18.4 \mu \mathrm{m}$ was treated with LEEI from two sides. A mean surface dose of $30.6 \pm 2.8 \mathrm{kGy}$ was applied (Fig. 4C). A minimum dose of $28.7 \mathrm{kGy}$ could be maintained throughout the entire sample (Fig. 4C). This dose is above the dose required for ionizing irradiation sterilization by different pharmacopoeia.

Since the penetration depth of LEEI is a critical limitation of this technology, we investigated the maximum thickness

Table 2. Sterility Test of Pericardia After Different Treatments

\begin{tabular}{lrcr}
\hline Treatment & Sterile, $\%$ & Nonsterile, $\%$ & $\mathrm{~N}$ \\
\hline Glutaraldehyde & 28 & 72 & 29 \\
Riboflavin/UV & 0 & 100 & 30 \\
Riboflavin/UV-LEEI & 100 & 0 & 30 \\
\hline
\end{tabular}

Samples were incubated for 14 days in caseine peptone soybean flower peptone bouillon at $30^{\circ} \mathrm{C}$. A clear solution was considered sterile, whereas a turbid solution was considered nonsterile $(n=29-30)$. 
FIG. 4. Simulation of dose distribution within the pericardial tissue during LEEI. (A) Thickness of differently treated pericardia (Table 1). Data are shown as means + $\mathrm{SD}(n=9)$. Statistically significant differences $(* p \leq 0.01$ and $* * p \leq 0.001)$ of the indicated groups were determined by the KruskalWallis test followed by Dunn's multiple comparisons test. (B) Experimental setup for modelling of the dose distribution within the pericardial tissue. Film dosimeters were assembled horizontally in a stack and irradiated from two sides. After irradiation, the film dosimeter stack was disassembled and the dose of every layer was analyzed.

(C) Various thicknesses of film dosimeter stacks were irradiated according to (B). Data are shown as means \pm $\mathrm{SD}(n=6)$. The lines indicate regression functions as obtained by polynomial regression for each depth profile.
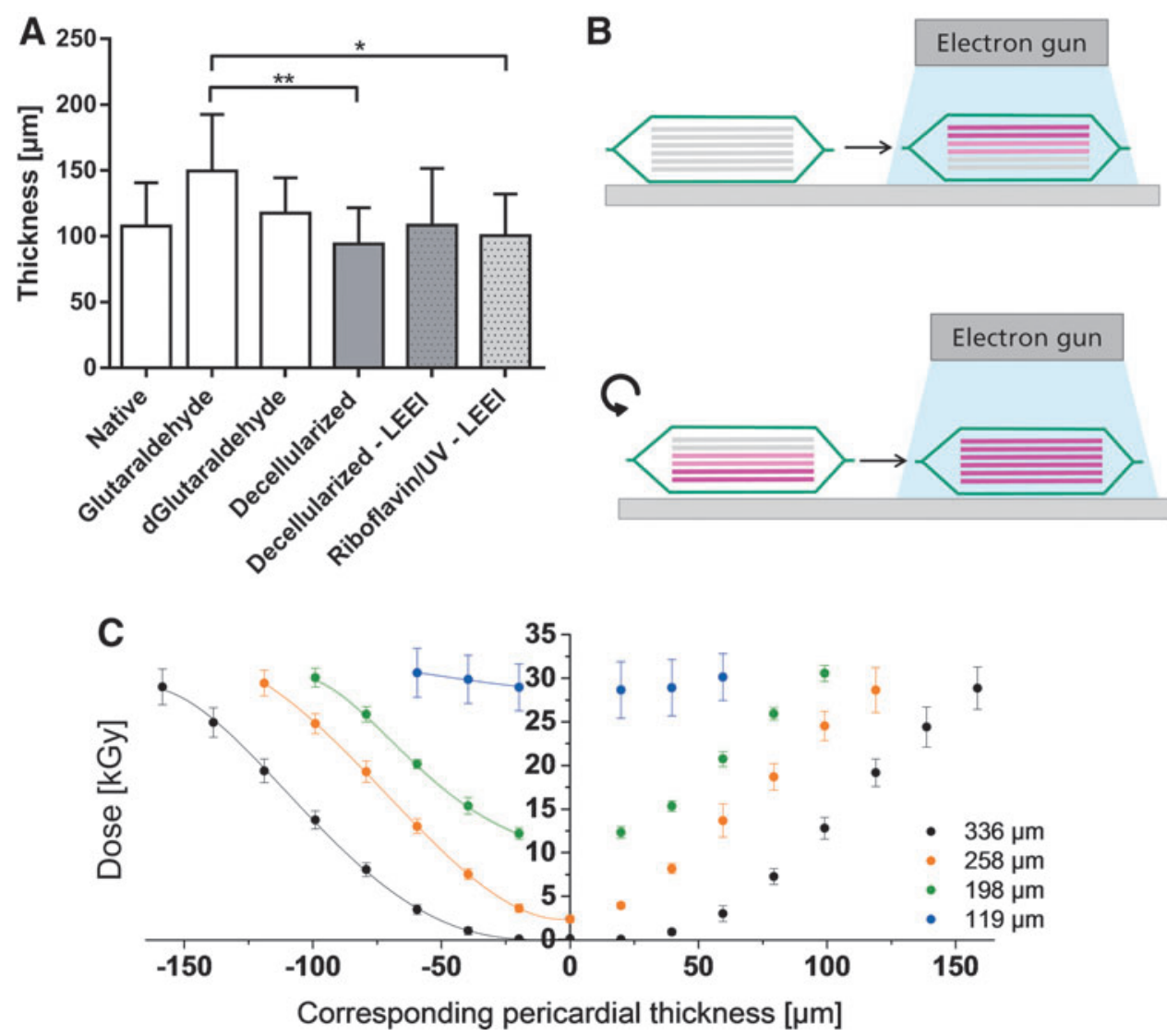

of a sample that did just pass the test for sterility, that is, on which no bacterial growth could be detected in the standard test. Various thicknesses of HDPE foil stacks were inoculated on the central layer with $1.5 \times 10^{6} \mathrm{CFU}$ B. pumilus spores, a reference bioindicator for validation of sterilization processes using ionizing irradiation, ${ }^{35}$ and LEEI was performed from two sides. Stacks up to a thickness of $175 \mu \mathrm{m}$ could be successfully sterilized. This experiment, however, does not provide information on the sterility assurance level (SAL) at this depth. A stack of $219 \mu \mathrm{m}$ as well as $285 \mu \mathrm{m}$ thickness could not be sterilized. A log reduction of $3.3 \pm 0.6$ and $0.1 \pm 0.1$ was achieved, respectively, for the central bacterial inoculation (Table 3 ).
To analyze the dose applied on the $B$. pumilus spores within the HDPE foil stack, corresponding thicknesses of film dosimeter stacks were irradiated from both sides and the dose administered on every layer was recorded (Fig. 4B). Doses of $11.2,2.5$, and $0.2 \mathrm{kGy}$ (for the thickness of 175, 219, and $285 \mu \mathrm{m}$ ) were applied to the B. pumilus spores (Fig. 4C, Table 3). To confirm that the applied and the calculated doses correspond, a film dosimeter was placed between two pericardia and treated with LEEI from two sides. Subsequently, the applied dose was analyzed and the theoretical dose was calculated by polynomial regression. The mean corresponding thickness of the pericardial sandwich was $193 \pm 4 \mu \mathrm{m}$ $(n=6)$. A dose of $9.5 \pm 2.6 \mathrm{kGy}(n=6)$ was determined on the

Table 3. Simulation of Sterilization DePth

\begin{tabular}{lccccccc}
\hline $\begin{array}{l}\text { Corresponding } \\
\text { pericardial } \\
\text { thickness, } \mu m\end{array}$ & $\begin{array}{c}\text { Inoculum, } \\
\text { CFU/cm }^{2}\end{array}$ & $\begin{array}{c}\text { CFU/cm } \\
\text { after LEEI }\end{array}$ & Log-reduction & Turbidity & $N$ & $\begin{array}{c}\text { Calculated } \\
\text { dose, } k G y\end{array}$ & $\begin{array}{c}\text { Calculated } \\
\text { log-reduction }\end{array}$ \\
\hline 44 & $1.5 \times 10^{6}$ & $<1$ & $\mathrm{na}$ & - & 3 & 29.7 & $>6$ \\
88 & $1.5 \times 10^{6}$ & $<1$ & $\mathrm{na}$ & - & 3 & 28.9 & $>6$ \\
132 & $1.5 \times 10^{6}$ & $<1$ & $\mathrm{na}$ & - & 3 & 22.4 & $>6$ \\
175 & $1.5 \times 10^{6}$ & $<1$ & $\mathrm{na}$ & - & 6 & 11.1 & $>6$ \\
219 & $1.5 \times 10^{6}$ & $1.3 \times 10^{3} \pm 2.1 \times 10^{3}$ & $3.3 \pm 0.6$ & + & 6 & 2.5 & 1.8 \\
285 & $1.5 \times 10^{6}$ & $8.1 \times 10^{5} \pm 5.8 \times 10^{5}$ & $0.1 \pm 0.1$ & + & 6 & 0.2 & 0.1 \\
\hline
\end{tabular}

High-density polyethylene foil stacks of the indicated thickness were inoculated with $>10^{6}$ CFU Bacillus pumilus spores per square centimeter in the middle and LEEI. Remaining bacteria were determined by viable counts as well as turbidity testing. The dose was calculated by polynomial regression based on the data of Figure $4 \mathrm{C}$. The log reduction was calculated by dividing the dose by the $\mathrm{D}_{10}$ value of $B$. pumilus spores. Data are shown as means \pm SD $(n=3-6)$. The measured log reduction and the calculated log reduction were compared by one sample $t$-test.

na, not applicable. 

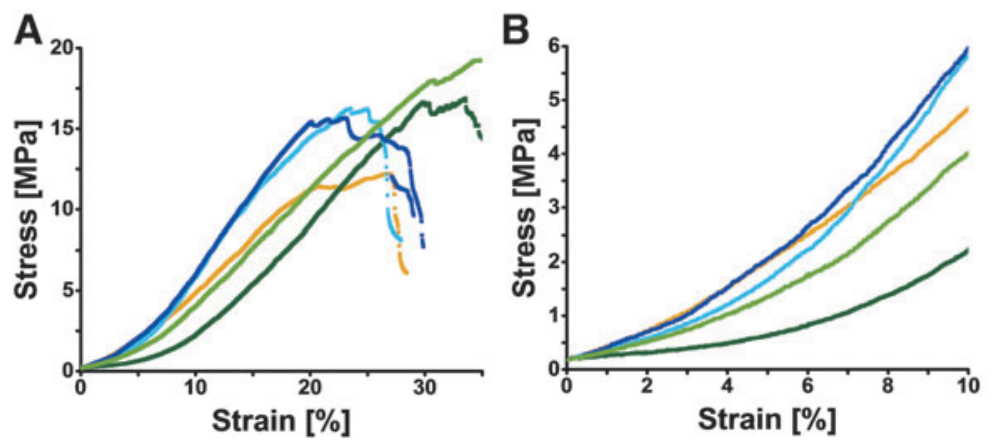

FIG. 5. Biomechanical analysis of differently treated pericardia. (A-B) Stressstrain curves of differently processed pericardia (Table 1).
Glutaraldehyde dGlutaraldehyde Decellularized Decellularized - LEEI Riboflavin / UV - LEEI (A) Complete stress-strain curve. (B) Magnified view on the physiologically relevant part of the stress-strain curve, that is, $0-10 \%$ strain. One representative curve out of $n=8$ is displayed. film dosimeter in the middle of the sandwich. The calculated dose accounted $7.8 \mathrm{kGy}$. The measured dose was not significantly different from the calculated dose (one sample $t$-test, $p=0.162$ ).

The $\mathrm{D}_{10}$ value describes the dose necessary to reduce a viable population by one power of $10 .{ }^{36} \mathrm{~A}_{10}$ value for LEEI of $1.4 \mathrm{kGy}$ was determined for B. pumilus by Gotzmann et al. ${ }^{37}$ By division of the applied dose by the $\mathrm{D}_{10}$ value, the $\log$ reduction was calculated. For a thickness of $285 \mu \mathrm{m}$, the calculated log reduction and the measured $\log$ reduction did not significantly differ (log reduction $0.1 \pm 0.1$, calculated $\log$ reduction $0.1, p=0.59$ ) (Table 3 ). The calculated $\log$ reduction for a thickness of $219 \mu \mathrm{m}$ was significantly lower compared with the measured log reduction (measured $\log$ reduction $3.3 \pm 0.6$, calculated $\log$ reduction $1.8, p=0.002)$.

\section{Biomechanical properties}

Uniaxial tensile tests were performed to analyze mechanical performance of LEEI pericardia. The stress strain curves are displayed in Figure 5A, B. There were no significant differences between the ultimate tensile strengths of any of the treatment groups $(p>0.05)$ (Table 4). Decellularized as well as nondecellularized glutaraldehyde-treated pericardia showed significantly higher strains at fracture $(p \leq 0.001$ and $p \leq 0.05)$ and significantly lower Young's moduli $(p \leq 0.05)$ compared with riboflavin/UV-LEEItreated pericardia. Measuring the stress at $10 \%$ strain, riboflavin/UV-LEEI-treated pericardia showed significantly higher stress values compared with glutaraldehyde-crosslinked pericardia $(p \leq 0.001$ and $p \leq 0.01)$.

\section{Cytocompatibility}

To evaluate putative toxicity of riboflavin/UV-LEEItreated pericardia, cytocompatibility was assessed by seed- ing HUVEC on the surface of differently treated pericardia and assessing the cell morphology, metabolic activity, and cell number. Fluorescence micrographs revealed a wellspread healthy morphology on riboflavin/UV-LEEI-treated pericardia (Fig. 6A, B). No changes between cells on riboflavin/UV-LEEI-treated pericardia and cells on decellularized pericardia could be detected regarding phenotype (Fig. 6A, B).

The relative overall metabolic activity of HUVEC on glutaraldehyde-treated pericardia was significantly lower compared with HUVEC on riboflavin/UV-LEEI-treated pericardia after 48 and $96 \mathrm{~h}(p \leq 0.01$ and $p \leq 0.001)$ (Fig. 6C). Additionally, the overall metabolic activity was significantly increased after $96 \mathrm{~h}$ compared with $48 \mathrm{~h}$ in all treatment groups except the glutaraldehyde group $(p \leq 0.001)$ (Fig. 6C). Quantification of the cell number revealed similar results (Fig. 6D).

Each manufacturer has an individual preservation regimen for pericardial patches and heart valves, including glutaraldehyde concentrations, washing regimens, and anticalcification post-treatments. Since those factors influence cell adhesion and viability on the tissue, two commercially available pericardial patches were analyzed. Ninety-six hours after HUVEC seeding, cells were rounded up on Supple Peri-Guard and Edwards bovine pericardial patch (Fig. 6B). The overall metabolic activity and the cell number of HUVEC on both Supple Peri-Guard and Edwards bovine pericardial patch were considerably lower compared with riboflavin/UV-LEEI-treated pericardia (Fig. 6C, D).

\section{Tissue morphology}

To assess the morphological changes in the tissue architecture caused by the different treatments, tissue surface microstructure was analyzed by scanning electron microscopy.

Table 4. Summary of Biomechanical Properties of Differently Processed Pericardia

\begin{tabular}{lcccc}
\hline Treatment & $\begin{array}{c}\text { Young's } \\
\text { modulus, } \mathrm{MPa}\end{array}$ & $\begin{array}{c}\text { Ultimate tensile } \\
\text { strength, } \mathrm{MPa}\end{array}$ & $\begin{array}{c}\text { Strain } \\
\text { at fracture, \% }\end{array}$ & $\begin{array}{c}\text { Stress at 10\% } \\
\text { strain, MPa }\end{array}$ \\
\hline Glutaraldehyde & $0.6 \pm 0.3^{*}$ & $17.4 \pm 9.6$ & $29.5 \pm 7.5^{*}$ & $2.9 \pm 0.9^{* * *}$ \\
dGlutaraldehyde & $0.6 \pm 0.2^{*}$ & $17.6 \pm 5.5$ & $33.8 \pm 10.6^{* * *}$ & $3.4 \pm 0.8^{* *}$ \\
Decellularized & $0.7 \pm 0.4$ & $11.5 \pm 4.2$ & $20.2 \pm 3.6$ & $4.5 \pm 1.6$ \\
Decellularized-LEEI & $0.9 \pm 0.3$ & $15.6 \pm 2.9$ & $23.3 \pm 4.5$ & $5.6 \pm 2.0$ \\
Riboflavin/UV-LEEI & $1.1 \pm 0.4$ & $17.6 \pm 8.6$ & $20.1 \pm 3.6$ & $6.4 \pm 1.8$ \\
\hline
\end{tabular}

Data are presented as means $\pm \operatorname{SD}(n=8)$. Statistically significant differences $(* p \leq 0.05, * * p \leq 0.01$, and $* * * p \leq 0.001)$ of groups compared with riboflavin/UV-LEEI-treated pericardia were analyzed by one-way analysis of variance followed by Bonferroni's multiple comparisons test. 
A qualitative assessment of tissue morphology of the different treatment groups is summarized in Supplementary Table S1 (Supplementary Data are available online at www.liebertpub.com/tec). Native pericardia showed a network of randomly oriented collagen fibers. The collagen network of decellularized pericardia was of a looser and more swollen morphology (Fig. 7A). In hematoxylin and eosin-stained tissue sections, fiber density was analyzed by quantification of the eosin-positive area fraction (Table 5). Glutaraldehyde-treated pericardia showed a tendency toward higher fiber densities compared with all other treatment groups (Table 5, Fig. 7B).

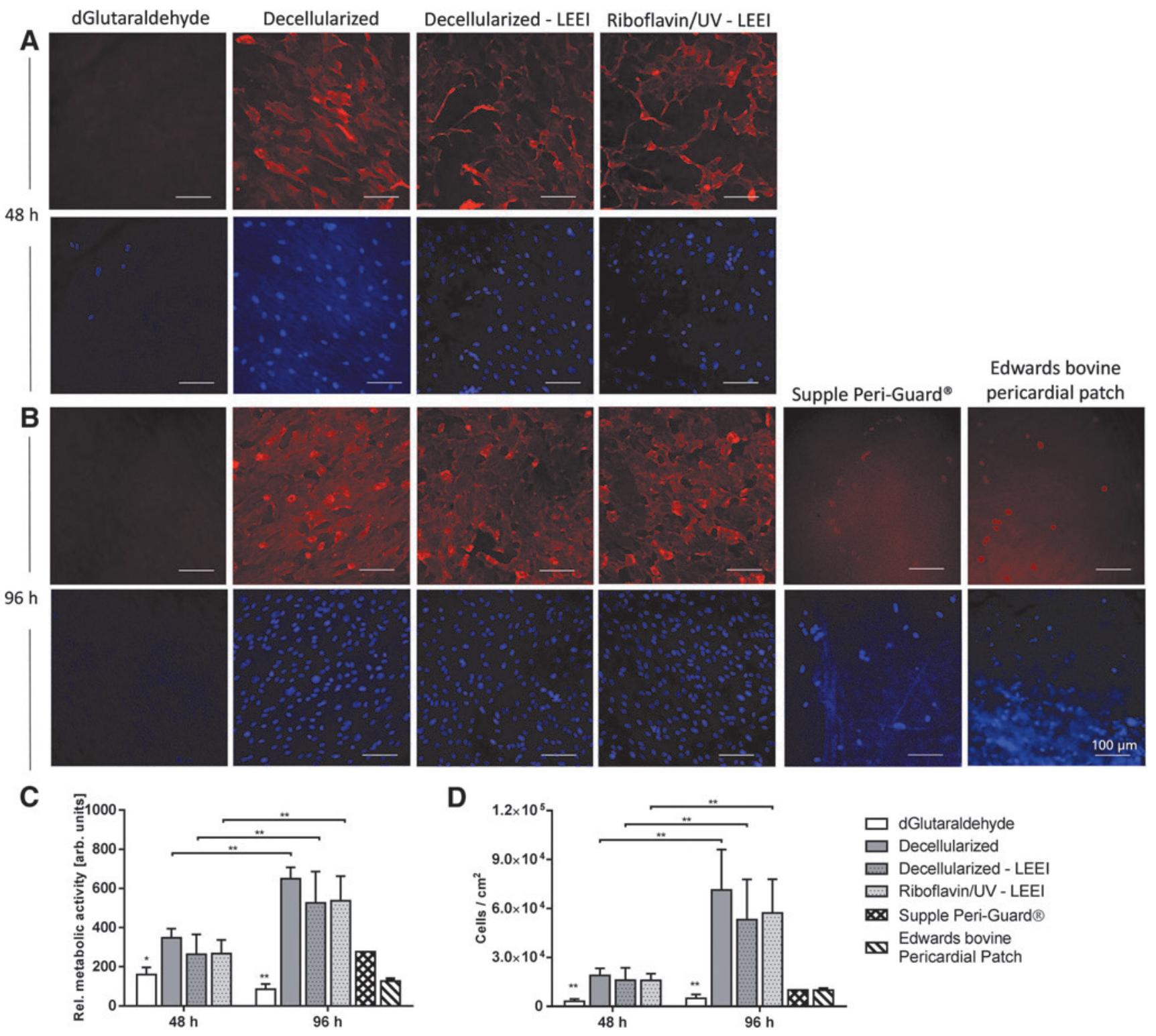

FIG. 6. Cytocompatibility of differently processed pericardia. (A, B) HUVEC were seeded on differently processed pericardial surfaces (Table 1) for (A) $48 \mathrm{~h}$ and (B) $96 \mathrm{~h}$. Cytoskeleton was stained using Phalloidin. Nuclei were stained using DAPI. Images are representative for $n=9$ or $n=1$ (Supple Peri-Guard and Edwards bovine pericardial patch) (scale bar: $100 \mu \mathrm{m}$ ). (C) Overall metabolic activity of HUVEC seeded on differently processed pericardia (Table 1$)$ for 48 and $96 \mathrm{~h}$, respectively. (D) HUVEC count per square centimeter after 48 or $96 \mathrm{~h}$ incubation on pericardia. Nuclei were stained with DAPI and quantified on fluorescence micrographs using CellProfiler software. Data are shown as means + SD $(n=9$ or $n=1$ [Supple Peri-Guard and Edwards bovine pericardial patch]). Statistically significant differences (* $p \leq 0.01$ and $* * p \leq 0.001$ ) of groups compared with riboflavin/UV-LEEI-treated pericardia were analyzed by one-way ANOVA followed by Bonferroni's multiple comparisons test. Differences between dGlutaraldehyde-treated samples and all other treatment groups after $48 \mathrm{~h}(p \leq 0.05)$ and $96 \mathrm{~h}(p \leq 0.001)$ were statistically significant. No further statistically significant differences were detected. Statistically significant differences $(* * p \leq 0.001)$ of overall metabolic activity and cell number after $48 \mathrm{~h}$ compared with after $96 \mathrm{~h}$ were analyzed by two-way ANOVA followed by Bonferroni's multiple comparisons test. Supple Peri-Guard ${ }^{\circledR}$ and Edwards bovine pericardial patch were not included into the statistical analysis due to small sample size. HUVEC, human umbilical vein endothelial cells. 

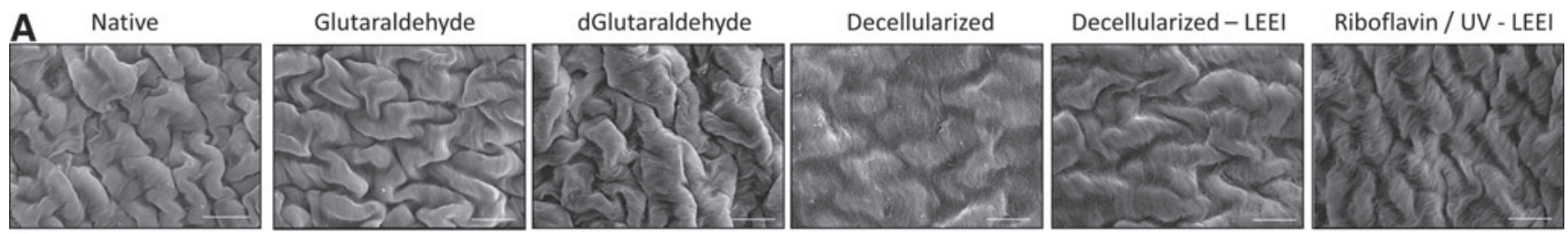

B
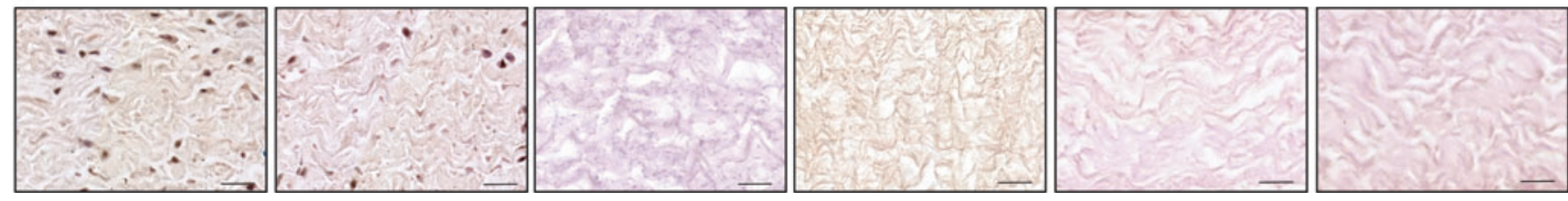

FIG. 7. Morphological analysis of differently processed pericardia. (A) Scanning electron micrographs (scale bar: $20 \mu \mathrm{m}$ ) and (B) hematoxylin and eosin staining (scale bar: $20 \mu \mathrm{m}$ ) of differently processed pericardia (Table 1). Images are representative for $n=3$.

\section{Discussion}

Pericardium-based tissue transplants encounter a limited life span due to degenerative processes and calcium deposition. ${ }^{1}$ The current gold standard of tissue preparation uses glutaraldehyde, which is associated with the accelerated graft failure. ${ }^{11-13}$ The replacement of glutaraldehyde has been suggested to lower susceptibility to calcification, promote endothelialization, and enhance tissue durability. ${ }^{18}$ Here, we report a novel toxin-free procedure to stabilize and sterilize pericardial tissue that combines photo-initiated UV cross-linking with LEEI.

\section{Decellularization efficiency}

Cellular remnants in transplantable tissues have been shown to increase immunogenicity as well as favor calcification and failure of tissue-engineered heart valves. ${ }^{38,39}$ Thus, a decellularization protocol was applied. According to Crapo et al., successful decellularization requires (1) the absence of nuclear material in hematoxylin and eosin-stained or DAPI-stained tissue sections and (2) less than $50 \mathrm{ng}$ of remaining DNA per mg of extracellular matrix. ${ }^{40}$ The absence of nuclear material in hematoxylin and eosin-stained tissue sections as well as a 70fold reduction in the DNA content were shown in Figure 2. The mean remaining DNA content was below the threshold defined by Crapo et al. Thus, the applied protocol, which was adopted from Roosens et al., ${ }^{29}$ was effective.

\section{Stabilization against premature biodegradation}

Digestion of transplantable tissues with collagenase is a model for the in vivo biodegradability after transplantation. ${ }^{41}$ Furthermore, it is an indirect method to estimate the cross-linking degree. A higher cross-linking degree leads to a decreased accessibility of the enzyme to cleavage sites as well as impaired penetration into deeper layers. ${ }^{42}$ LEEI by itself was not able to increase the tissue's resistance to collagenase. Schönfelder ${ }^{34}$ has even observed a dosedependent decrease in enzymatic resistance with increasing doses using comparable parameters. Thus, various crosslinkers and radical scavengers were evaluated for the modulation of tissue stability once combined with LEEI. However, glucose, ascorbate, or riboflavin in combination with LEEI were unable to significantly influence tissue resistance to collagenase. In contrast, Ohan and Dunn found an increase in enzymatic resistance and mechanical properties of collagen films after gamma irradiation in the presence of glucose. ${ }^{15}$ Seto et al. showed a protective effect on tendons after electron irradiation in the presence of glucose and riboflavin but not with ascorbate. ${ }^{14}$ These discrepancies may originate from differences in tissue architecture as well as variation in experimental procedures. Nevertheless, cross-linking with UV in the presence of riboflavin and subsequent LEEI significantly decreased the pericardial digestion rate, thus significantly increasing the stability compared with decellularized pericardia. Wollensak et al. have shown successful cross-linking by riboflavin and UV on human corneae. ${ }^{43}$ Weadock et al. showed increased mechanical strength of bovine dermal collagen after UV irradiation. ${ }^{44}$

Compared with glutaraldehyde-treated pericardia, all evaluated procedures reached significantly lower enzymatic resistances. Tedder et al. showed that moderate cross-linking tolerates cell infiltration and gradual remodeling after subdermal implantation of porcine pericardia in rats. ${ }^{45}$ In accordance, Umashankar et al. observed remodeling potential and no

Table 5. Quantification of the Fiber Density of Differently Treated Pericardia

\begin{tabular}{lcccccc}
\hline Treatment & Native & Glutaraldehyde & dGlutaraldehyde & Decellularized & $\begin{array}{c}\text { Decellularized- } \\
\text { LEEI }\end{array}$ & $\begin{array}{c}\text { Riboflavin/ } \\
\text { UV-LEEI }\end{array}$ \\
\hline Fiber density, \% area & $87.7 \pm 8.3$ & $91.0 \pm 2.7$ & $88.7 \pm 1.5$ & $82.8 \pm 10.2$ & $77.0 \pm 3.0$ & $80.5 \pm 3.7$ \\
\hline
\end{tabular}

Fiber density was analyzed by quantification of the eosin-positive area fraction in hematoxylin and eosin-stained tissue sections of differently treated pericardia (Table 1$)$. Data are presented as means \pm SD $(n=10$ randomly selected areas of three to four different animals and two to three different tissue sections each). No statistically significant differences between treatment groups were detected using Kruskal-Wallis test followed by Dunn's multiple comparisons test. 
apparent signs of calcification of decellularized bovine pericardia after subcutaneous implantation in rats. Glutaraldehyde-treated patches, on the contrary, did not show signs of remodeling and exhibited calcification. ${ }^{46}$ Additionally, biodegradability has been suggested to be essential for tissue remodeling since degraded extracellular matrix peptides are believed to act as chemoattractant for several progenitor cells in vitro. ${ }^{47}$ Thus, a moderate degradation rate could be favorable. Simultaneously, a cytocompatible surface may prevent scaffold failure due to complete degradation by infiltrating cells. Jiang et al. could show replacement of degraded tissue by endogenous tissue with collagen membranes after subcutaneous implantation in rats. ${ }^{42}$ This process could not be observed with glutaraldehyde-cross-linked tissue. ${ }^{48}$

\section{Effectiveness of irradiation and penetration depth}

Sterility is a prerequisite for tissue grafts. Here, we could sterilize riboflavin/UV-LEEI-treated decellularized pericardial scaffolds applying a minimum dose of $28.7 \mathrm{kGy}$. This dose is above the dose required for sterilization by ionizing irradiation by different pharmacopoeia; thus, a sufficient SAL can be assumed. Due to the homogeneous dose distribution, not only microorganisms on the tissue surface but also within the tissue could be successfully sterilized. Despite large variation in the bioburden between batches and potential variations in the kind of microorganisms, sterility was obtained in all samples. Additionally, LEEI was shown to be an effective procedure for inactivation of viruses by Fertey et al. ${ }^{22}$ Kowalski et al. observed a bioburden estimate of up to $2.8 \times 10^{4}$ CFU on human and animal tissue grafts. ${ }^{49}$ The bioburden determined in this study exceeds this value by one $\log _{10}$ level. This difference may originate from the high precautions taken during removal of tissue grafts compared with tissue removal for meat production.

One of the major challenges of LEEI is a limited penetration depth. ${ }^{28,33}$ Therefore, the maximum thickness of the pericardia that encounter no remaining viable bacteria on the tissue after LEEI was modeled by challenging different thicknesses of HDPE foil disks with $>10^{6}$ B. pumilus spores in the central layer. B. pumilus spores serve as reference bioindicator for validation of sterilization processes using ionizing radiation because of their resistance to radiation. ${ }^{35}$ The dose required to reduce the viable bacterial load by $90 \%$ (one log level) is indicated as $\mathrm{D}_{10}$ value. ${ }^{36}$ For $B$. pumilus spores, a $\mathrm{D}_{10}$ value of $1.2 \mathrm{kGy}$ was indicated by the manufacturer (MesaLabs) using a Cobald 60 source. Using LEEI, a $\mathrm{D}_{10}$ value of $1.4 \mathrm{kGy}$ was determined by Gotzmann et al. ${ }^{37}$ Thus, gamma irradiation and LEEI have comparable $\mathrm{D}_{10}$ values. Considering the $\mathrm{D}_{10}$ value, $8.4 \mathrm{kGy}$ are theoretically required to eradicate six decimal powers of $B$. pumilus spores. Consistently, when $11.1 \mathrm{kGy}$ reached the center of a $175 \mu \mathrm{m}$ thick pericardial tissue, $>10^{6} \mathrm{~B}$. pumilus spores were inactivated. The mean thickness of all treatment groups lay below $175 \mu \mathrm{m}$.

For conformation of the dose calculations, a film dosimeter was placed between two pericardia and treated with LEEI. There were no significant differences between the applied and the calculated doses confirming the applied model. For thicknesses above $175 \mu \mathrm{m}$, the log reduction was calculated using the $\mathrm{D}_{10}$ value as well as the applied dose and compared with the log reduction measured by viable counts. The measured log reduction lay above the calculated $\log$ reduction confirming the expected inactivation effectiveness of $B$. pumilus spores by LEEI.

The parameters for LEEI used in this study were customized for porcine pericardial tissue. By adjusting those parameters, further tissues or scaffolds may be sterilized likewise. The penetration depth can be substantially increased by increasing the accelerating voltage from 150 to $300 \mathrm{kV}$. An accelerating voltage of $300 \mathrm{kV}$ is included in the range of low-energy. Concurrently, only a minor increase in shielding requirements occurs. ${ }^{33}$ Furthermore, the density of freeze-dried tissues is considerably lower than the density of wet tissues. This influences the penetration depth positively. Thus, tissues and scaffolds substantially thicker than porcine pericardia may also be sterilized by LEEI after customization of the parameters used for LEEI.

\section{Mechanical suitability}

Mechanical performance is crucial for the suitability of the pericardial scaffolds for the intended application. Unfavorable mechanical properties may lead to graft failure and reoperations. For repair of abdominal wall defects, Deeken and Lake recommend an ultimate tensile strength of at least $20 \mathrm{MPa}$ and a strain at fracture between $10 \%$ and $30 \%$ using a strain rate of $25 \mathrm{~mm} / \mathrm{min}^{50}$ The mean strain at fracture of riboflavin/ UV-LEEI-treated pericardia of $20.1 \%$ fits this criterion. After riboflavin/UV and LEEI treatment, the mean ultimate tensile strength lies just below the threshold recommended by Deeken and Lake. Thus, the analysis of the ultimate tensile strength during recurrent mechanical stress should be assessed to evaluate the suitability. The mean ultimate tensile strength of decellularized pericardia increased after riboflavin/UV and LEEI treatment $(11.5 \pm 4.2 \mathrm{MPa}$ vs. $17.6 \pm 8.6 \mathrm{MPa})$, but the increase was not statistically significant.

The mechanical requirements for patches for vascular reconstruction majorly depend on the site of transplantation. Miyamotto et al., for example, observed an ultimate tensile strength of $19 \mathrm{MPa}$ for a glutaraldehyde-treated pericardial patch for carotid enderectomy. ${ }^{51}$ Thus, the ultimate tensile strength of $17.6 \pm 8.6 \mathrm{MPa}$ determined in this study for riboflavin/UV-LEEI-treated scaffolds seems to be within a favorable range.

The mechanical deformation of a human heart valve during opening and closing is estimated to be $10 \% .{ }^{52}$ All treated samples are within the linear region of the stress-strain curve at $10 \%$ elongation. Thus, the deformation is expected to be fully reversible. However, the stress at $10 \%$ strain of glutaraldehyde-treated tissue is significantly lower compared with riboflavin/UV-LEEI-treated pericardia. Increased tissue stress may favor calcification of bioprosthetic heart valves. ${ }^{53}$ Thus, it needs to be investigated whether this higher stress induces adverse events in the absence of glutaraldehyde. In accordance to Arbeiter et al. as well as Kayed et al., we report an increase in the strain at fracture of glutaraldehyde-treated pericardia compared with native tissue. ${ }^{54,55}$

\section{Cytocompatibility}

Toxicity is a major drawback associated with glutaraldehydetreated pericardia. ${ }^{13}$ Due to the inability of cells to adhere and survive for longer periods on glutaraldehyde-treated tissue, 
formation of functional cell layers on the tissue surface as well as remodeling are not likely to occur. ${ }^{48,56}$ In accordance, little cell attachment and no cell proliferation was observed on glutaraldehyde-treated pericardia. To confirm that this lack of cell adhesion and proliferation is not associated with poor washing and tissue preparation, two commercially available glutaraldehyde-treated pericardial patches were evaluated. Similar results were obtained, although both tissues underwent different procedures for glutaraldehyde cross-linking and additional treatments to suppress calcification. On riboflavin/UV and LEEI scaffolds, however, no decrease in overall metabolic activity or cell number compared with decellularized pericardia was shown. After $96 \mathrm{~h}$, the cell number significantly increased compared with samples analyzed after $48 \mathrm{~h}$, which may indicate cell survival and proliferation on riboflavin/UV-LEEI-treated pericardial scaffolds. Thus, formation of a functional endothelial cell lining by endogenous endothelial cells in vivo appears feasible. Complete recellularization with endothelial cells creates an endogenous interface and establishes a nonthrombogenic surface. ${ }^{57}$ Moreover, xenogeneic antigens are masked and thus prevent foreign body reactions. ${ }^{58}$ Furthermore, endothelial cells have shown protective effects against tissue calcification. ${ }^{58}$ Scattered endothelial cells, as on glutaraldehyde-treated pericardia, are not sufficient to evoke those beneficial effects. In contrast, a confluent endothelial cell layer on riboflavin/UV-LEEI-treated pericardia may contribute to prolonging the tissue's durability in vivo.

\section{Tissue morphology}

Tissue microstructure was analyzed by scanning electron microscopy and hematoxylin and eosin staining. Glutaraldehyde-treated samples tended to have higher fiber densities compared with all other treatment groups. This may indicate an increase in cross-linking, which is accompanied by a change in tissue morphology. The difference in fiber density between riboflavin/UV-LEEItreated pericardia and native pericardia was smaller compared with the difference in fiber density between glutaraldehydetreated pericardia and native pericardia. This may indicate that the tissue stabilization obtained by the SULEEI procedure, which was shown by an increase in enzymatic resistance of riboflavin/UV-LEEI-treated pericardia, is not accompanied with major morphological changes.

Roosens et al., who established the decellularization procedure applied here, showed increased spaces between collagen fibers and a considerable loss in elastin and glycosaminoglycan content. ${ }^{29}$ A loosening of the fiber density as an effect of decellularization could also be derived as a trend from our data. It is further expected that, in accordance with Roosens et al., a loss in elastin and glycosaminoglycan content in riboflavin/UV-LEEI-treated pericardia might have occurred.

\section{Opportunities of LEEI}

Effects of ionizing irradiation on tissue morphology mainly depend on the substrate and the process parameters applied. ${ }^{33}$ During ionizing irradiation, the occurrence of free radicals leads to the eradication of pathogens as well as nonspecific modifications of the substrate. ${ }^{20}$ Fertey et al. and Bayer et al. showed that virus protein structures, for example, were not significantly altered after LEEI with an applied dose of $30 \mathrm{kGy}$. The preservation of surface protein structures was demonstrated by in vitro antibody binding as well as by in vivo formation of neutralizing antibodies in mice. $^{21,22}$ Thus, LEEI seems nondetrimental to protein structures. In line with those findings, the presented data indicate only minor morphological changes caused by LEEI. In contrast, gamma irradiation has been reported to affect collagen structure by fibril reorganization, protein denaturation, fragmentation, and condensation. ${ }^{14,25-27}$ HEEI has been shown to decrease the failure load of patellar tendon allografts by applying a dose of $34 \mathrm{kGy} .{ }^{24}$ This decrease in mechanical properties could not be restored after implantation in sheep. ${ }^{23}$ In contrast, no impairment in the ultimate tensile strength of riboflavin/UV-LEEI-treated pericardia occurred by applying a dose of $31 \mathrm{kGy}$.

LEEI applies the required dose for sterilization of $25 \mathrm{kGy}$ within several milliseconds. Thus, the exposure time to a noncontrolled ionized atmosphere is reduced to a minimum and prevents unintended tissue damage. ${ }^{21,22}$ Gotzmann $^{59}$ has shown a significant influence of the exposure time on the effect of ionizing irradiation. In contrast, HEEI and gamma irradiation require several seconds and several hours, respectively, to apply equal doses. ${ }^{33}$ This may contribute to the tissue damage by gamma irradiation and HEEI, as described previously. Moreover, thermal effects of LEEI are negligible. Thus, heat-induced collagen degradation by LEEI is not of concern, whereas thermal effects have to be considered during HEEI and gamma irradiation.

For X-ray shielding during LEEI, $8 \mathrm{~mm}$ of lead were sufficient in this study. This allows the integration of an LEEI facility directly at the location of the user such as in hospitals, tissue banks, or good manufacturing practice laboratories. Thus, LEEI enables novel applications in a small and cost-effective facility. Since shielding requirements exponentially rise with increasing accelerating voltages and decreasing density of the shielding material, ${ }^{60}$ HEEI and gamma irradiation require heavy shielding (a few meters of concrete) and specialized companies. ${ }^{33}$

\section{Conclusion}

In this study, the novel SULEEI procedure for sterilization and stabilization of decellularized pericardial scaffolds by photo-initiated UV cross-linking and LEEI was developed. Compared with glutaraldehyde-treated pericardial scaffolds and commercial pericardial patches, riboflavin/UV-LEEI-treated pericardial scaffolds showed substantially improved cytocompatibility. Additionally, the ultimate tensile strength of riboflavin/UV-LEEI-treated pericardia was maintained. Conversely, impairment in mechanical strength is of concern after HEEI and gamma irradiation of collagen-rich tissues. Thus, this may be a promising alternative procedure for processing of pericardium-based tissue transplants and potentially other thin tissue transplants. Nonetheless, further analysis including calcification analysis and in vivo testing is needed for complete evaluation of the suitability as pericardium-based tissue transplant. Moreover, the adjustment and implementation of the SULEEI procedure for further tissues and biomaterials showing equal thicknesses, densities, and geometries including amniotic membranes and hydrogels may possibly broaden the applications in the future. 


\section{Acknowledgments}

The authors acknowledge Dr. Claudia Dittfeld, Department of Cardiac Surgery, Technische Universität Dresden, Germany, for her support during the histological analysis. The authors also acknowledge Lysann Kenner and André Poremba for technical assistance as well as Juliane Schötz for assistance during sterilization experiments.

\section{Disclosure Statement}

The method described in this article is part of an issued patent (DE 102016121982 B3) and an IP application (WO 2018/091553 A1).

\section{References}

1. Singhal, P., Luk, A., and Butany, J. Bioprosthetic heart valves: impact of implantation on biomaterials. ISRN Biomater 2013, 1, 2013.

2. Cantore, G., Guidetti, B., and Delfini, R. Neurosurgical use of human dura mater sterilized by gamma rays and stored in alcohol: long-term results. J Neurosurg 66, 93, 1987.

3. Limpert, J.N., Desai, A.R., Kumpf, A.L., Fallucco, M.A., and Aridge, D.L. Repair of abdominal wall defects with bovine pericardium. Am J Surg 198, e60, 2009.

4. Ishihara, T., Ferrans, V.J., Jones, M., Boyce, S.W., and Roberts, W.C. Structure of bovine parietal pericardium and of unimplanted Ionescu-Shiley pericardial valvular bioprostheses. J Thorac Cardiovasc Surg 81, 747, 1981.

5. Matsagas, M.I., Bali, C., Arnaoutoglou, E., et al. Carotid endarterectomy with bovine pericardium patch angioplasty: mid-term results. Ann Vasc Surg 20, 614, 2006.

6. Schmidt, C.E., and Baier, J.M. Acellular vascular tissues: natural biomaterials for tissue repair and tissue engineering. Biomaterials 21, 2215, 2000.

7. Kingsnorth, A., and LeBlanc, K. Hernias: inguinal and incisional. Lancet 362, 1561, 2003.

8. Siddiqui, R.F., Abraham, J.R., and Butany, J. Bioprosthetic heart valves: modes of failure. Histopathology 55, 135, 2009.

9. Goo, H.C., Hwang, Y.S., Choi, Y.R., Cho, H.N., and Suh, $\mathrm{H}$. Development of collagenase-resistant collagen and its interaction with adult human dermal fibroblasts. Biomaterials 24, 5099, 2003.

10. Badylak, S.F., and Gilbert, T.W. Immune response to biologic scaffold materials. Semin Immunol 20, 109, 2008.

11. Arcidiacono, G., Corvi, A., and Severi, T. Functional analysis of bioprosthetic heart valves. J Biomech 38, 1483, 2005.

12. van Steenberghe, M., Schubert, T., Guiot, Y., Bouzin, C., Bollen, X., and Gianello, P. Enhanced vascular biocompatibility of decellularized xeno-/allogeneic matrices in a rodent model. Cell Tissue Bank 18, 249, 2017.

13. Gendler, E., Gendler, S., and Nimni, M.E. Toxic reactions evoked by glutaraldehyde-fixed pericardium and cardiac valve tissue bioprosthesis. J Biomed Mater Res 18, 727, 1984.

14. Seto, A., Gatt, C.J., and Dunn, M.G. Radioprotection of tendon tissue via crosslinking and free radical scavenging. Clin Orthop Relat Res 466, 1788, 2008.

15. Ohan, M.P., and Dunn, M.G. Glucose stabilizes collagen sterilized with gamma irradiation. J Biomed Mater Res A 67, 1188, 2003.

16. Han, B., Jaurequi, J., Tang, B.W., and Nimni, M.E. Proanthocyanidin: a natural crosslinking reagent for stabilizing collagen matrices. J Biomed Mater Res A 65, 118, 2003.
17. Sung, H.-W., Chang, W.-H., Ma, C.-Y., and Lee, M.-H. Crosslinking of biological tissues using genipin and/or carbodiimide. J Biomed Mater Res A 64, 427, 2003.

18. Connolly, J.M., Alferiev, I., Clark-Gruel, J.N., et al. Triglycidylamine crosslinking of porcine aortic valve cusps or bovine pericardium results in improved biocompatibility, biomechanics, and calcification resistance: chemical and biological mechanisms. Am J Pathol 166, 1, 2005.

19. DIN EN ISO 11137: Sterilization of health care productsRadiation-Part 2. Establishing the sterilization dose. Berlin: Beuth, 2012.

20. Alizadeh, E., Sanz, A.G., García, G., and Sanche, L. Radiation damage to DNA: the indirect effect of low energy electrons. J Phys Chem Lett 4, 820, 2013.

21. Bayer, L., Fertey, J., Ulbert, S., and Grunwald, T. Immunization with an adjuvanted low-energy electron irradiation inactivated respiratory syncytial virus vaccine shows immunoprotective activity in mice. Vaccine 36, 1561, 2018.

22. Fertey, J., Bayer, L., Grunwald, T., et al. Pathogens inactivated by low-energy-electron irradiation maintain antigenic properties and induce protective immune responses. Viruses 8, 2016.

23. Schmidt, T., Hoburg, A., Broziat, C., et al. Sterilization with electron beam irradiation influences the biomechanical properties and the early remodeling of tendon allografts for reconstruction of the anterior cruciate ligament (ACL). Cell Tissue Bank 13, 387, 2012.

24. Hoburg, A.T., Keshlaf, S., Schmidt, T., et al. Effect of electron beam irradiation on biomechanical properties of patellar tendon allografts in anterior cruciate ligament reconstruction. Am J Sports Med 38, 1134, 2010.

25. Bowes, J.H., and Moss, J.A. The effect of gamma radiation on collagen. Radiat Res 16, 211, 1962.

26. Cheung, D.T., Perelman, N., Tong, D., and Nimni, M.E. The effect of gamma-irradiation on collagen molecules, isolated alpha-chains, and crosslinked native fibers. J Biomed Mater Res 24, 581, 1990.

27. Gouk, S.-S., Lim, T.-M., Teoh, S.-H., and Sun, W.Q. Alterations of human acellular tissue matrix by gamma irradiation: histology, biomechanical property, stability, in vitro cell repopulation, and remodeling. J Biomed Mater Res B Appl Biomater 84, 205, 2008.

28. Sílíndír, M., and Özer, A.Y. Sterilization methods and the comparison of E-beam sterilization with gamma radiation sterilization. FABAD J Pharm Sci 43, 2009.

29. Roosens, A., Somers, P., Somer, F. de, Carriel, V., van Nooten, G., and Cornelissen, R. Impact of detergent-based decellularization methods on porcine tissues for heart valve engineering. Ann Biomed Eng 44, 2827, 2016.

30. Helt-Hansen, J., Miller, A., Sharpe, P., Laurell, B., Weiss, D., and Pageau, G. D $\mu-A$ new concept in industrial lowenergy electron dosimetry. Radiat Phys Chem 79, 66, 2010.

31. Abd El-Naby Radwan, M., El-Monaem, S., Bashandy, A., and El-Ghamry, A. Evaluation and microbiological investigations of radiation sterilization of disposable blood tubing set. Int J Adv Res in Biol Sci 17, 17, 2016.

32. Aijaz, A., Faulknor, R., Berthiaume, F., and Olabisi, R.M. Hydrogel microencapsulated insulin-secreting cells increase keratinocyte migration, epidermal thickness, collagen fiber density, and wound closure in a diabetic mouse model of wound healing. Tissue Eng A 21, 2723, 2015.

33. Schiller, S., Heisig, U., and Panzer, S. Electron Beam Technology. New York: Wiley, 1982. 
34. Schönfelder, J. [Low-energy electron irradiation for sterilization and surface modification of transplant tissue]. Niederenergetische Elektronenstrahltechnologie zur Sterilisation und Oberflächenmodifizierung von Transplantatgeweben. [Dissertation]. Technische Universität, Dresden, 2015.

35. Tirumalai, R.S. Biological Indicators for Sterilization: Pharmacopeial Forum, 6th ed. 2006. www.pharmacopeia .cn/v29240/usp29nf24s0_c1035.html, accessed January 30, 2018.

36. Dziedzic-Goclawska, A., Kaminski, A., UhrynowskaTyszkiewicz, I., and Stachowicz, W. Irradiation as a safety procedure in tissue banking. Cell Tissue Bank 6, 201, 2005.

37. Gotzmann, G., Portillo, J., Wronski, S., et al. Low-energy electron-beam treatment as alternative for on-site sterilization of highly functionalized medical products-a feasibility study. Radiat Phys Chem 150, 9, 2018.

38. Courtman, D.W., Pereira, C.A., Kashef, V., McComb, D., Lee, J.M., and Wilson, G.J. Development of a pericardial acellular matrix biomaterial: biochemical and mechanical effects of cell extraction. J Biomed Mater Res 28, 655, 1994.

39. Simon, P., Kasimir, M.T., Seebacher, G., et al. Early failure of the tissue engineered porcine heart valve SYNERGRAFT in pediatric patients. Eur J Cardiothorac Surg 23, 1002; discussion 1006, 2003.

40. Crapo, P.M., Gilbert, T.W., and Badylak, S.F. An overview of tissue and whole organ decellularization processes. Biomaterials 32, 3233, 2011.

41. Gorham, S.D., Hyland, T.P., French, D.A., and Willins, M.J. Cellular invasion and breakdown of three different collagen films in the lumbar muscle of the rat. Biomaterials 11, 113, 1990.

42. Jiang, B., Wu, Z., Zhao, H., et al. Electron beam irradiation modification of collagen membrane. Biomaterials 27, 15, 2006.

43. Wollensak, G., Spoerl, E., and Seiler, T. Riboflavin/ ultraviolet-a-induced collagen crosslinking for the treatment of keratoconus. Am J Ophthalmol 135, 620, 2003.

44. Weadock, K.S., Miller, E.J., Bellincampi, L.D., Zawadsky, J.P., and Dunn, M.G. Physical crosslinking of collagen fibers: comparison of ultraviolet irradiation and dehydrothermal treatment. J Biomed Mater Res 29, 1373, 1995.

45. Tedder, M.E., Liao, J., Weed, B., et al. Stabilized collagen scaffolds for heart valve tissue engineering. Tissue Eng A 15, 1257, 2009.

46. Umashankar, P.R., Mohanan, P.V., and Kumari, T.V. Glutaraldehyde treatment elicits toxic response compared to decellularization in bovine pericardium. Toxicol Int 19, 51, 2012.

47. Li, F., Li, W., Johnson, S., Ingram, D., Yoder, M., and Badylak, S. Low-molecular-weight peptides derived from extracellular matrix as chemoattractants for primary endothelial cells. Endothelium 11, 199, 2004.

48. Morticelli, L., Thomas, D., Roberts, N., Ingham, E., and Korossis, S. Investigation of the suitability of decellularized porcine pericardium in mitral valve reconstruction. $\mathbf{J}$ Heart Valve Dis 22, 340, 2013.

49. Kowalski, J.B., Merritt, K., Gocke, D., and Osborne, J. Assessment of bioburden on human and animal tissues: part 2-results of testing of human tissue and qualification of a composite sample for routine bioburden determination. Cell Tissue Bank 13, 431, 2012.

50. Deeken, C.R., and Lake, S.P. Mechanical properties of the abdominal wall and biomaterials utilized for hernia repair. $\mathrm{J}$ Mech Behav Biomed Mater 74, 411, 2017.

51. Miyamotto, M., Del Valle, C.E., Moreira, R.C.R., and Timi, J.R.R. Resistência tensional do pericárdio bovino fixado em glutaraldeído comparada com a da veia safena magna. J vasc Bras 8, 103, 2009.

52. Lo, D., and Vesely, I. Biaxial strain analysis of the porcine aortic valve. Ann Thorac Surg 60, S374, 1995.

53. Thubrikar, M.J., Deck, J.D., Aouad, J., and Nolan, S.P. Role of mechanical stress in calcification of aortic bioprosthetic valves. J Thorac Cardiovasc Surg 86, 115, 1983.

54. Arbeiter, D., Grabow, N., Wessarges, Y., Sternberg, K., and Schmitz, K.-P. Suitability of porcine pericardial tissue for heart valve engineering: biomechanical properties. Biomed Eng Biomed Tech 57, 882, 2012.

55. Kayed, H.R., Sizeland, K.H., Kirby, N., Hawley, A., Mudie, S.T., and Haverkamp, R.G. Collagen cross linking and fibril alignment in pericardium. RSC Adv 5, 3611, 2015.

56. Gulbins, H., Goldemund, A., Anderson, I., et al. Preseeding with autologous fibroblasts improves endothelialization of glutaraldehyde-fixed porcine aortic valves. J Thorac Cardiovasc Surg 125, 592, 2003.

57. Weng, Y., Chen, J., Tu, Q., Li, Q., Maitz, M.F., and Huang, N. Biomimetic modification of metallic cardiovascular biomaterials: from function mimicking to endothelialization in vivo. Interface Focus 2, 356, 2012.

58. Polak, R., Rodas, A.C.D., Chicoma, D.L., et al. Inhibition of calcification of bovine pericardium after treatment with biopolymers, E-beam irradiation and in vitro endothelization. Mater Sci Eng C Mater Biol Appl 33, 85, 2013.

59. Gotzmann, G. [Low-energy electron beam modification of diamond-like carbon coatings for biofunctional coatings of implant materials]. Elektronenstrahlmodifizierung von diamantähnlichen Kohlenstoffschichten zur biofunktionalen Beschichtung von Implantatmaterialien. Technische Universität, Dresden, 2017.

60. Lead Industries Association Inc. A Guide to the Use of Lead for Radiation Shielding. www.canadametal.com/wpcontent/uploads/2016/08/radiation-shielding.pdf, accessed April 23, 2018, 1984.

Address correspondence to: Jessy Schönfelder Fraunhofer Institute for Organic Electronics Electron Beam and Plasma Technology FEP Winterbergstraße 28 Dresden 01277

Germany

E-mail: jessy.schoenfelder@fep.fraunhofer.de

Received: September 28, 2018

Accepted: November 8, 2018

Online Publication Date: December 12, 2018 